\title{
Temporal Analysis of Reference Frames in Parietal Cortex Area 5d during Reach Planning
}

\author{
Lindsay R. Bremner and Richard A. Andersen \\ Division of Biology, California Institute of Technology, Pasadena, California 91125
}

The neural encoding of spatial and postural reference frames in posterior parietal cortex has traditionally been studied during fixed epochs, but the temporal evolution of these representations (or lack thereof) can provide insight into the underlying computations and functions of this region. Here we present single-unit data recorded from two rhesus macaques during a reach planning task. We found that area $5 \mathrm{~d}$ coded the position of the hand relative to gaze before presentation of the reach target, but switched to coding the target location relative to hand position soon after target presentation. In the pretarget period the most relevant information for success in the task is the position of the hand relative to gaze; however, after target onset, the most task-relevant spatial relationship is the location of the target relative to the hand. The switch in coding suggests that population activity in area $5 \mathrm{~d}$ may represent postural and spatial information in the reference frame that is most pertinent at each stage of the task. Moreover, although target-hand coding was dominant from soon after the reach target onset, this representation was not static but built in strength as movement onset approached, which we speculate could reflect a role for this region in building an accurate state estimate for the limb. We conclude that representations in area $5 \mathrm{~d}$ are more flexible and dynamic than previously reported.

Key words: monkey; neurophysiology; parietal; reaching; reference frames

\section{Introduction}

During movement planning, the brain uses incoming sensory information about the location of a target to compute the appropriate motor commands for action. For visually guided reaching, the coding of the target is transformed from a retinotopic, or gaze-centered, reference frame to a hand or body-centered reference frame, with reciprocal circuits between multimodal parietal cortex and frontal regions thought to be critical for this sensorimotor transformation (Caminiti et al., 1998; Andersen and Cui, 2009). The temporal stability of reference frames within identified subregions of posterior parietal cortex is currently an open question that has implications for the computation underlying sensorimotor transformations. If a particular reference frame within a subregion is maintained consistently throughout a trial, this would suggest that the transformation occurs via simultaneous recruitment and readout of separate, dedicated, subregions (Buneo et al., 2008). Alternatively, if the encoding within a subregion evolves over the course of a trial, this would indicate a sequential transformation process that can occur within a single

\footnotetext{
Received May 15, 2013; revised Feb. 26, 2014; accepted Feb. 28, 2014.

Author contributions: L.R.B. and R.A.A. designed research; L.R.B. performed research; L.R.B. analyzed data; L.R.B. and R.A.A. wrote the paper.

This work was supported by National Institutes of Health Grant EY005522. We thank Tessa Yao for editorial assistance, Kelsie Pejsa and Viktor Shcherbatyuk for technical assistance, and Igor Kagan for magnetic resonance imaging.

The authors declare no competing financial interests.

Correspondence should be addressed to Lindsay R. Bremner, Division of Biology, Mail Code 156-29, California Institute of Technology, Pasadena, CA 91125. E-mail: lindsay@caltech.edu.

DOI:10.1523/JNEUROSCI.2068-13.2014

Copyright $\odot 2014$ the authors $\quad 0270-6474 / 14 / 345273-12 \$ 15.00 / 0$
}

area, as well as demonstrate flexibility of representations within an area.

Despite some heterogeneity among individual cells (Avillac et al., 2005; Chang and Snyder, 2010; McGuire and Sabes, 2011), identified subregions in posterior parietal cortex appear to code in distinct and systematic reference frames. For example, in the parietal reach region (PRR) the target is represented predominantly in a gaze-centered reference frame (Andersen et al., 1998; Batista et al., 1999; Buneo et al., 2002; Cohen and Andersen, 2002; Pesaran et al., 2006), whereas the dorsal aspect of area 5 (area 5d) shows positional tuning during stationary posture (Georgopoulos et al., 1984; Lacquaniti et al., 1995) and codes upcoming targets mainly in a hand-centered reference frame (Bremner and Andersen, 2012). However, few studies have addressed the question of temporal stability; most previous work examined only a single, relatively short, epoch during reach planning. One study reported that reference frames in both area $5 \mathrm{~d}$ and PRR are invariant with respect to time following target onset (Buneo et al., 2008), whereas another group reported trends for shifts toward gaze-centered encoding in both these areas as the task progressed (McGuire and Sabes, 2011). However, neither experiment used sufficient variables to be able to test thoroughly for all combinations of gaze-centered $(\mathrm{T}-\mathrm{G})$, hand-centered $(\mathrm{T}-\mathrm{H})$, and handgaze $(\mathrm{H}-\mathrm{G})$ coding. A sufficient number of variables are required to distinguish reference frames from eye and limb position gain effects (Bremner and Andersen, 2012).

To assess the temporal stability of reference frames during reach planning, we used a range of target, hand, and gaze positions and analyzed firing rates in area $5 \mathrm{~d}$ with a sliding window and across multiple epochs. We found that population activity in area $5 \mathrm{~d}$ was more dynamic than previously reported: the position 
of the hand relative to gaze was encoded in the fixation period, but this representation declined after target presentation. Furthermore, coding of the target position relative to the hand emerged early in the task but increased in strength during the reach planning period, suggesting that this area may be involved in aspects of movement planning downstream from the actual sensorimotor transformation.

\section{Materials and Methods}

Two adult male rhesus monkeys (Macaca mulatta, G and T) participated in this study. All surgical and animal care procedures were conducted in accordance with National Institutes of Health guidelines and were approved by the California Institute of Technology Animal Care and Use Committee.

\section{Behavioral task}

The behavioral paradigm was a delayed reaching task under visual fixation, as illustrated in Figure $1 A$ and described previously (Pesaran et al., 2006; Bremner and Andersen, 2012). Each animal was trained to fixate his gaze $(G)$ on a red square at one of four possible horizontal starting locations $\left(-20^{\circ},-10^{\circ}, 0^{\circ}\right.$, or $10^{\circ}$ in screen-centered coordinates) and touch a green square at one of the same four positions with his left hand (H). After successfully maintaining the $\mathrm{H}$ and $\mathrm{G}$ fixation positions for $1 \mathrm{~s}$, a second green square (the target, $\mathrm{T}$ ) was illuminated. The target position was also located $-20^{\circ},-10^{\circ}, 0^{\circ}$, or $10^{\circ}$ horizontally and $16^{\circ}$ either above or below the fixation positions, depending on which vertical position best activated the recorded cell. The monkey continued to hold the ocular and manual fixations for a variable delay period $(1.2-1.5 \mathrm{~s})$ until the initial manual fixation point was extinguished, at which point he made a reach to the target location without breaking visual fixation. If the monkey successfully acquired the target within $0.7 \mathrm{~s}$ and then held his hand on it for $0.25 \mathrm{~s}$ without moving his gaze, he was rewarded with a drop of juice. Eye position was monitored with an infrared eye-tracking camera (ISCAN; Arrington Research). Reaches were made within the frontal plane formed by the touchscreen (Elo TouchSystems), which was at a distance of $30 \mathrm{~cm}$ (monkey G) or $26 \mathrm{~cm}$ (monkey T) from the eyes. Behavioral tolerance windows had radii of $4^{\circ}$ (eye fixation) and $5^{\circ}$ (initial hand position and target). The $\mathrm{G}, \mathrm{H}$, and $\mathrm{T}$ positions were varied independently across trials, giving a total of $4 \times 4 \times 4=64$ different trial types.

\section{Data collection}

Single-unit recordings were made with $\sim 1-2 \mathrm{M} \Omega \mathrm{Pt} / \mathrm{Ir}$ microelectrodes in a single-channel microdrive (FHC) from the posterior portion of dorsal area 5 (area $5 \mathrm{~d}$ ), in the surface cortex adjacent to the medial bank of the intraparietal sulcus (IPS; Fig. 1B). The center of the cluster of recordings for monkey T was $\sim 1.25 \mathrm{~mm}$ lateral and $1 \mathrm{~mm}$ anterior to the center of recordings in monkey $\mathrm{G}$. Recordings from both animals spanned $\sim 3$ $\mathrm{mm}$ rostral to the IPS and were between 0.14 and $3.5 \mathrm{~mm}$ in depth from the estimated cortical surface, with a median depth of $0.93 \mathrm{~mm}$. Cells in the recorded area are distinct from those in the nearby PRR both anatomically and functionally. PRR is located deeper in the IPS, and PRR cells generally show a clear response to cue onset and have higher peak firing rates than cells in area $5 \mathrm{~d}$. The dataset of cells reported here is the same as that collected for Bremner and Andersen (2012). Recorded neural activity was passed through a headstage, then filtered $(154 \mathrm{~Hz}-8.8$ $\mathrm{kHz}$ ), amplified, and digitized (Plexon) and saved for off-line sorting (Plexon Offline Sorter) and analysis (MATLAB 7.8; MathWorks). The main reference frame task was run only when a well isolated, spatially tuned cell had been identified. Spatial tuning was assessed in a standard center-out reaching task. In some sessions, additional well isolated neurons were recorded on the same electrode: these were included in the dataset regardless of spatial tuning.

\section{Data analysis}

Only single units with a minimum of three trials per condition were included in the dataset. Data were aligned to reach target onset for the fixation ( -450 to $-50 \mathrm{~ms})$ and early delay $(200-600 \mathrm{~ms})$ epochs, and to movement onset for the late delay epoch ( -500 to $-100 \mathrm{~ms})$. To identify underlying reference frames as distinct from gain field effects (Andersen and Mountcastle, 1983), we analyzed firing rate matrices for individual cells as follows:

Firing rate matrices. For each pair of variables (TH, TG, HG), we constructed four 4-by-4 matrices of mean firing rates, with each element in a matrix corresponding to a unique combination of hand position, gaze position, and target location. For example, an individual hand-gaze (HG) matrix represents the firing rates for all 16 different arrangements of starting hand and gaze positions, but with target position constant at, say, $-20^{\circ}$ in all trials. The remaining three $\mathrm{HG}$ matrices have the same hand and gaze structure, but are composed of trials in which the target was located at $-10^{\circ}, 0^{\circ}$, or $10^{\circ}$, respectively. Epoch analyses were conducted on only one matrix per variable pair at the peak response for the third variable, to maximize the signal-to-noise ratio. For example, in Figure $2 B$, late delay epoch, $\mathrm{H}$, was constant at $10^{\circ}$ for the TG matrix, $\mathrm{G}$ was constant at $-10^{\circ}$ for the TH matrix, and T was constant at $-20^{\circ}$ for the HG matrix. The temporal analysis was conducted on the full set of 12 matrices for each cell.

Gradient analysis. We used a combination of gradient analysis and singular value decomposition (SVD) of the matrices to assess how each variable affects the firing rate of individual cells at different stages of the task (Peña and Konishi, 2001; Buneo et al., 2002; Pesaran et al., 2006, 2010). The gradient of a matrix was estimated with the MATLAB gradient function and plotted as red arrows on the matrix elements. The directions and lengths of the set of red arrows indicate the relative importance of each variable on the firing rate of the cell. For example, in Figure $2 B$, late delay epoch, $\mathrm{HG}$ matrix, the arrows predominantly point left and right, reflecting the dominance that changes in $\mathrm{H}$ have over changes in $\mathrm{G}$ on the firing rate for this cell in this epoch. The circular plots beneath each matrix essentially summarize this information into a single resultant. However, the coordinate framework matrices often show a symmetrical pattern (as in the HG matrix example described above), so gradient elements would cancel each other out during calculation of the resultant. To avoid this, we doubled the angle for each gradient element before computing the resultant. We visualized this resultant angle on circular plots from $0^{\circ}$ to $\pm 180^{\circ}$ with $0^{\circ}$ representing a left-right pattern of red arrows, $\pm 180^{\circ}$ representing an up-down pattern of red arrows, and $-90^{\circ}$ representing arrows pointing to the diagonal (Fig. 2B). Each circular plot is notated with the appropriate variable or combination of variables to aid with interpretation (for example, $\mathrm{H}$ at $0^{\circ}, \mathrm{G}$ at $\pm 180^{\circ}, \mathrm{H}-\mathrm{G}$ at $-90^{\circ}$, and $\mathrm{H}+\mathrm{G}$ at $+90^{\circ}$ in an HG matrix). The angle of the gradient resultant therefore indicates the overall orientation of the coordinate bias and hence the relative influence of each variable within a pair on the firing rate.

Each coordinate framework matrix was classed as tuned if the resultant length was significantly greater than the resultant length calculated after randomization of the matrix elements (randomization test). Rayleigh's test was used to assess the uniformity of circular histograms for tuned resultant angles ( $p<0.05$, with Bonferroni correction for multiple comparisons). Previous studies have referred to the individual coordinate frame matrices as response fields for a cell (Pesaran et al., 2006, 2010; Bremner and Andersen, 2012). To minimize confusion with spatial response fields, we have avoided this usage here. In place of terms such as "response field orientation," we refer more explicitly to "orientation of the gradient resultant."

Singular value decomposition. Although the gradient analysis can tell us whether there is significant tuning within a matrix and to which variable(s) a cell responds the most, it cannot distinguish between important patterns of coding. For example, the relationship between firing rate and a pair of variables for a given cell may be best described as a gain relationship:

$$
\text { Firing rate }=f(T) . f(H) \text {, }
$$

where the response to one variable is scaled by the value of the second variable. In this example, the effects of each variable on firing rate are by definition multiplicatively separable. For a different cell, the relationship may take a vector form:

$$
\text { Firing rate }=f(T-H) \text {, }
$$


A

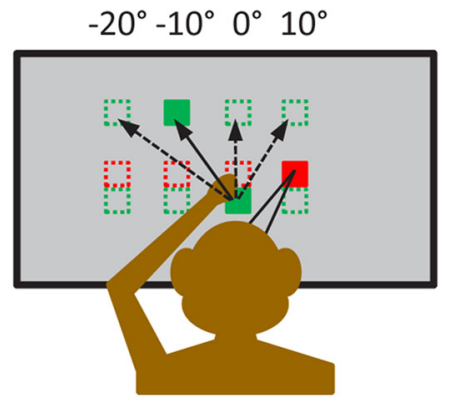

B

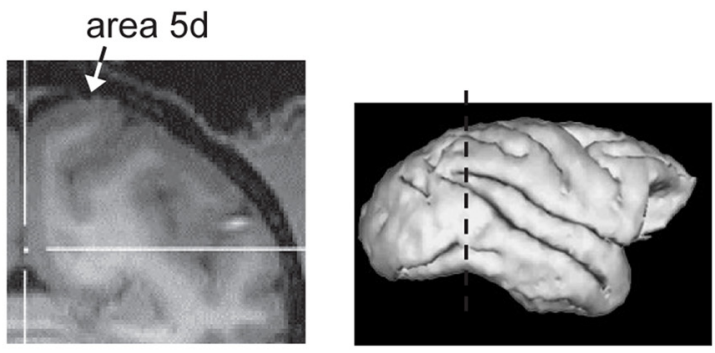

Figure 1. $A$, The reference frame reaching task. Gaze fixation (red squares), starting hand position (lower green squares), and targets (upper green squares) were located at $-20^{\circ},-10^{\circ}, 0^{\circ}, 0$ or $10^{\circ}$ horizontally. $\boldsymbol{B}$, Coronal fMRI section from monkey $\mathrm{G}$ showing the area $5 \mathrm{~d}$ recording site.

where the two variables $T$ and $H$ form part of the same function and cannot be multiplicatively separated from each other (inseparable). In such a case, the peak of the tuning curve for one variable is inextricably linked to the position of the second variable, creating a distinctive bottom-left to upper-right diagonal pattern in the response matrix (Fig. $2 B$, fixation epoch, HG matrix and late delay epoch, TH matrix). For the $\mathrm{T}-\mathrm{H}$ example, the vector relationship can also be referred to as coding the target in a hand-centered reference frame, or coding the target relative to the hand position. A gradient resultant pointing to $\mathrm{T}+\mathrm{H}$ (or $\mathrm{T}+\mathrm{G}$ or $\mathrm{H}+\mathrm{G}$ ) would indicate that the underlying matrix had a peak response pattern aligned with the opposite diagonal (upper left to bottom right). A separable $\mathrm{T}+\mathrm{H}$ relationship would be produced if $\mathrm{T}$ and $\mathrm{H}$ were independent factors with opposite monotonic spatial tuning: this would create a peak in the upper left or lower right corner of the matrix. An inseparable $\mathrm{T}+\mathrm{H}$ ( or $\mathrm{T}+\mathrm{G}$ or $\mathrm{H}+\mathrm{G}$ ) relationship has no intuitive explanation and, in fact, is rarely observed (Fig. 6A).

SVD was used to determine whether the relationship between pairs of variables was separable (in other words, a multiplicative, gain relationship) or inseparable (vector relationship). For the example TH matrix, SVD reduces the matrix to a weighted sum where the weights $\left(s_{1}, s_{2}\right.$, etc.) are known as the singular values:

$$
f(T, H)=s_{1} t_{1}(T) h_{1}(H)+s_{2} t_{2}(T) h_{2}(H)+\cdots .
$$

If the first singular value is very large such that the second and further terms are insignificant, then the matrix can be adequately described by the first term alone:

$$
f(T, H)=s_{1} t_{1}(T) h_{1}(H),
$$

which is a gain relationship identical to Equation 1. If two or more singular values are necessary to capture the response matrix, then $\mathrm{T}$ and $\mathrm{H}$ are inseparable and their relationship cannot be modeled as a gain effect of one variable on the other. Matrices were mean-subtracted before performing the SVD. A matrix was classified as separable if the first singular value was significantly large $(p<0.05)$ when compared with the first singular value obtained after randomization of the matrix elements. Otherwise, the matrix was deemed inseparable. It has been shown previously using simulated data from idealized neuronal responses that this method is sufficiently sensitive to detect gain fields with as few as three trials per condition (Pesaran et al., 2010).

Time-step analysis: For each cell, we calculated the resultant length and angle of the coordinate framework gradient in $200 \mathrm{~ms}$ windows positioned at $100 \mathrm{~ms}$ intervals. Firing rates were aligned to the target onset from $1000 \mathrm{~ms}$ before to $800 \mathrm{~ms}$ after reach target onset, and to movement onset from $800 \mathrm{~ms}$ before to $1000 \mathrm{~ms}$ after the start of the reach. The length of the resultant at each time step is an indication of the strength of the tuning or coordinate bias at that point in time. For the population sliding analysis, we calculated the mean resultant from the entire population of 128 recorded cells at each time step for each variable pair. Arrow lengths for the population analysis are therefore normalized within a variable pair. An arrow length equal to one would indicate that the gradient resultant had the same orientation in all cells for that variable pair at that time step.
Firing rate-reaction time correlation. For each cell-trial-type combination, we calculated the correlation between firing rate and reaction time on a trial-by-trial basis. As a comparison, we broke any correlation between firing rate and reaction time by randomizing the reaction times with respect to the firing rate within each cell-trial-type combination and repeating the analysis on the shuffled data. We compared the mean correlation coefficient of the actual dataset with the mean correlation coefficients from 1000 shuffled datasets to assess significance.

\section{Results}

We recorded extracellular spiking activity in parietal area $5 \mathrm{~d}$ while monkeys performed a visually guided delayed reaching task. We isolated activity from 292 cells in total; 67\% (196/292) of these had spatially tuned, reach-related activity as assessed in a center-out screening task (see Materials and Methods). The main task was designed to have a large number of independent combinations of hand, gaze, and target positions so that we could assess the contributions of each of these variables on cell firing rate. Specifically, we used four hand positions, four gaze positions, and four target locations (Fig. 1A). This large number of trial types $(4 \times 4 \times 4=64)$ resulted in some cells losing isolation before enough trial repetitions had been completed: these cells were excluded from the database. Two monkeys were trained in the task before recordings began until their success rates plateaued. Typical success rates were $78-84 \%$ trials correct for monkey G and $70-78 \%$ trials correct for monkey T. Reaction times were comparable for both animals with means (and SDs) of 314 (132) ms for monkey G and 289 (120) ms for monkey T. Our eventual database consisted of 128 well isolated cells in total,79 cells from monkey $\mathrm{G}$ and 49 cells from monkey $\mathrm{T}$, with data pooled across animals in all analyses.

\section{Changes in reference frame coding within a single cell}

Figure $2 A$ illustrates the responses of a sample cell, with firing aligned to the movement onset. During the delay period, this cell showed particularly robust firing whenever the horizontal displacement of the target was $10^{\circ}$ to the left of the starting hand position [i.e., target $(\mathrm{T})$ at $0^{\circ}$ and hand $(\mathrm{H})$ at $10^{\circ}$, $\mathrm{T}$ at $-10^{\circ}$ and $\mathrm{H}$ at $0^{\circ}, \mathrm{T}$ at $-20^{\circ}$ and $\mathrm{H}$ at $\left.-10^{\circ}\right]$. In other words, this cell codes the target location in a hand-centered reference frame, also referred to as the extrinsic reach vector $\mathrm{T}-\mathrm{H}$, as previously reported for the population of area $5 \mathrm{~d}$ cells (Bremner and Andersen, 2012). This result can be seen more clearly in the three firing-rate matrices of spiking during the late delay epoch (500100 ms before movement onset; Fig. 2B, bottom). Each 4-by-4 matrix represents the mean firing rates for 16 trial types in which one of the three variables was held constant at the location, which elicited the peak response while the remaining two variables were 
A

$10^{\circ}$
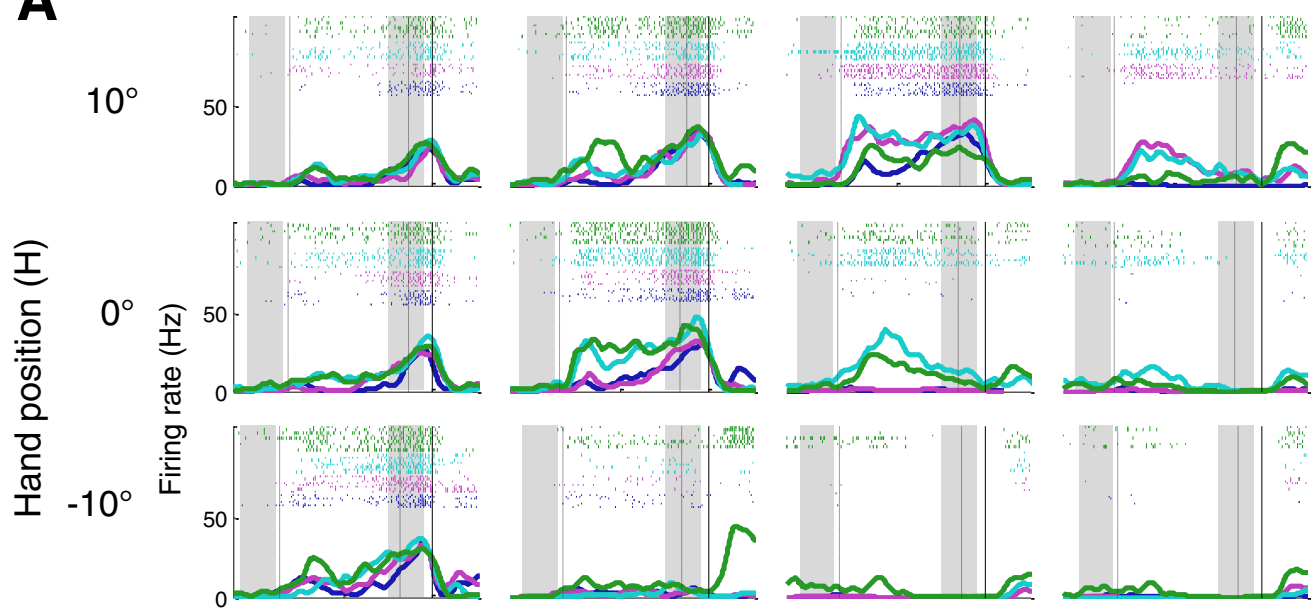

Gaze
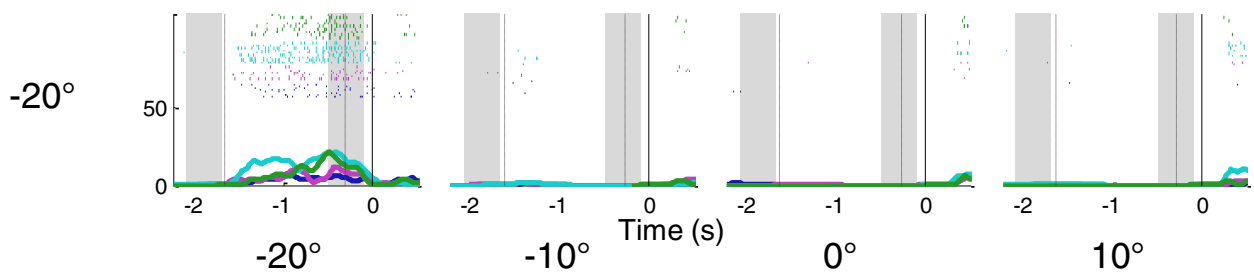

position

Target position (T)

B

TG

$\mathrm{TH}$

HG
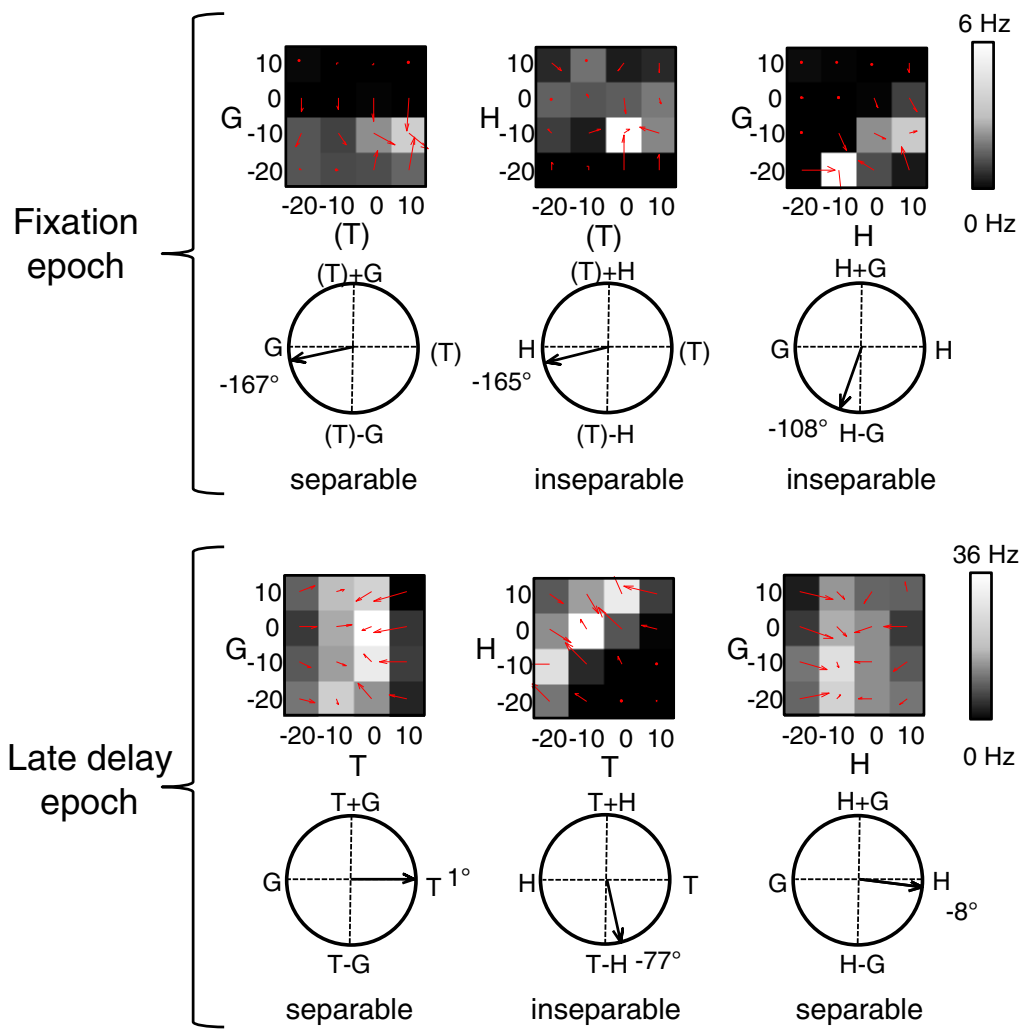

inseparable

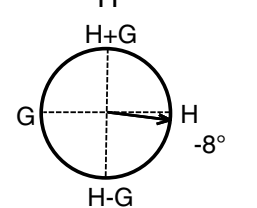

separable

Figure 2. Example area $5 \mathrm{~d}$ cell with hand-gaze encoding in the fixation epoch and target-hand coding in the late delay epoch. A, Peristimulus time histograms and raster plots for all 64 conditions. Each subplot shows the response of the neuron to a particular combination of target position and hand position, for all four possible gaze fixation positions. Trials are aligned to movement onset with the dashed lines indicating the mean target onset and go signal, respectively. The shaded regions designate the fixation and late delay epochs. $\boldsymbol{B}$, Matrices and gradient resultant orientations for the cell shown in $\boldsymbol{A}$ during the fixation (top) and late delay (bottom) epochs. 


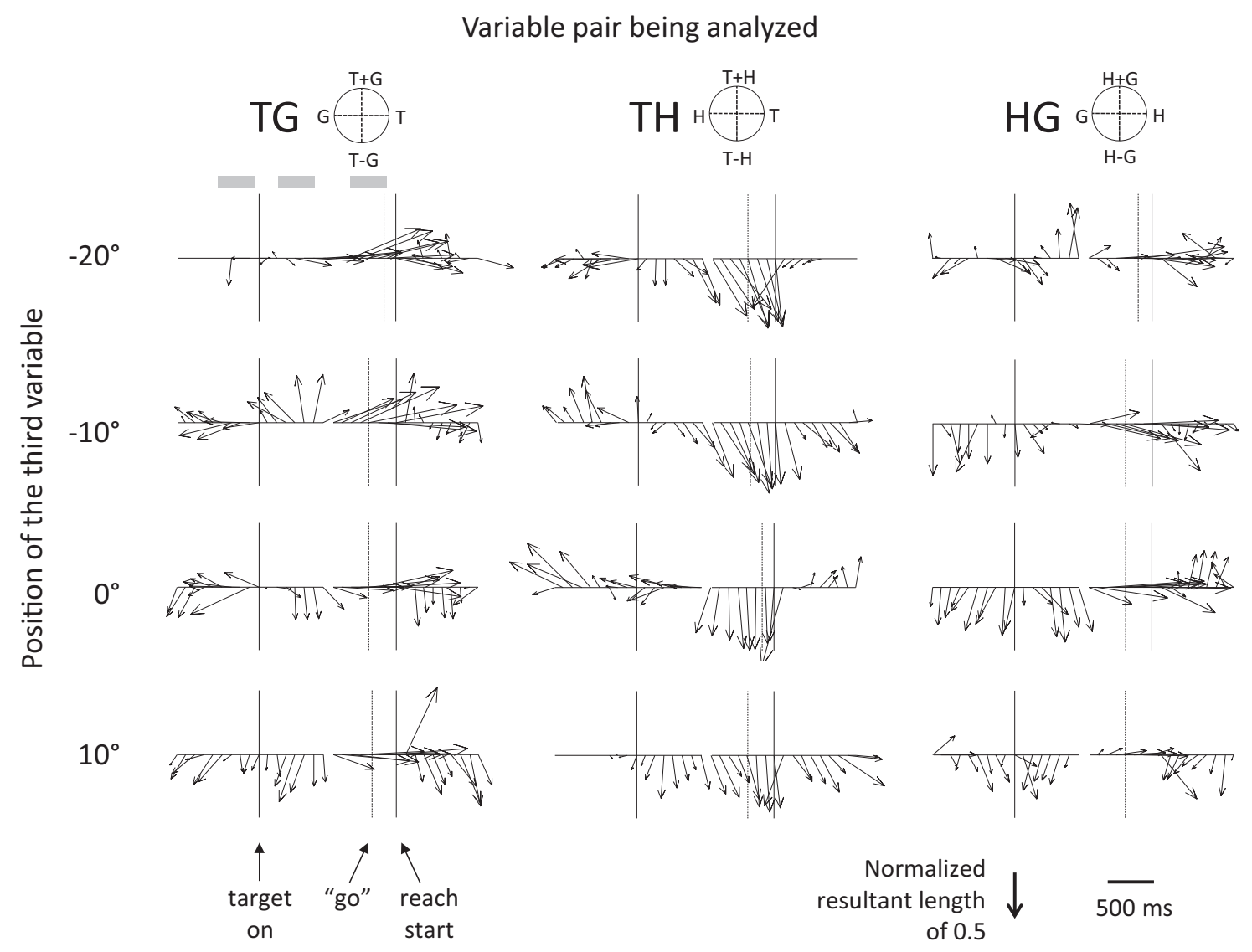

Figure 3. Time-step analysis for the example cell shown in Figure 2. Each column shows the response of the cell to a pair of variables (e.g., TG) at each of the four positions for the third variable (e.g., H). In each subplot, the arrows represent the orientation of the matrix gradient resultant calculated for a $200 \mathrm{~ms}$ window centered at $100 \mathrm{~ms}$ intervals through the trial. Circular plots at the top of each column indicate the appropriate interpretation of arrow direction for each variable pair. Arrow length indicates tuning strength. Data were aligned to target onset (first solid vertical line) for the first 17 time steps and to movement onset (second solid vertical line) for the second 17 time steps, with a short gap indicating the break in alignment. The vertical dashed line indicates the mean go signal and the three shaded boxes at top left show the fixation, early delay, and late delay epochs.

each allowed to vary from -20 to $10^{\circ}$. The $\mathrm{TH}$ matrix for this cell has a gradient resultant angle of $-77^{\circ}$ (referred to in previous studies as a response field orientation of $-77^{\circ}$; Pesaran et al., 2006, 2010; Bremner and Andersen, 2012). This shows that changes in target and hand position both influence the firing rate to a similar degree. The inseparable nature of this matrix indicates the relationship between the two variables has a vector form $(\mathrm{T}-\mathrm{H}$; equivalent to $\mathrm{H}-\mathrm{T})$ rather than being a simple gain effect of hand position $\left[f(H)^{\star} f(T)\right.$; see Materials and Methods]. Furthermore, the TG and HG late delay period matrices for this cell encoded $\mathrm{T}\left(1^{\circ}\right)$ and $\mathrm{H}\left(-8^{\circ}\right)$, respectively, confirming that gaze location had little influence on the firing rate of the cell during this epoch. Figure $2 B$, top, however, shows the firing rate matrices for the same cell during the fixation epoch, before presentation of the target. Despite the low firing rate and subsequent noisiness of the mean responses at this point, the cell is clearly influenced by gaze location as well as hand position and the HG matrix shows a diagonal pattern indicative of coding the hand position relative to the direction of gaze $\left(-108^{\circ}\right.$ and inseparable; $\mathrm{H}-\mathrm{G}$ vector encoding, equivalent to $\mathrm{G}-\mathrm{H}$ ).

To investigate this change in reference frame coding in more detail, we conducted a sliding window time-step analysis of gradient resultants during the task, starting after the animal acquired the initial hand and gaze fixation points and ending after acquisition of the reach target. Figure 3 illustrates the results of this analysis for the sample cell described above. The direction of the arrows at each time step indicates which of the variables in each pair influences the firing rate the most, and the length of each arrow indicates the strength of the tuning at that moment in time. The center column shows that the reach vector $\mathrm{T}-\mathrm{H}$ is instantiated in the firing rate within $\sim 600 \mathrm{~ms}$ of the target appearance, but that it increases in strength as the delay period progresses, peaking just before the reach onset. The right column confirms weaker but generally consistent $\mathrm{H}-\mathrm{G}$ coding in the pretarget period that either decays or shifts to encoding only the hand position as the movement approaches. $\mathrm{T}-\mathrm{G}$ encoding for this cell is somewhat sporadic and inconsistent through the early part of the delay period, with target position eventually becoming the dominant influence on firing in the late part of the delay period.

\section{Evolution of population responses}

We applied the sliding window analysis to all 128 cells recorded from area $5 \mathrm{~d}$ and pooled the results to assess how the population response evolves during the task (Fig. 4). In this figure the population resultants are normalized within each variable pair. The population resultants for $\mathrm{TH}$ demonstrate that the predominantly hand-centered reference frame previously reported for this region is present shortly after the target appears, consistent with previous reports (Fig. 4, center; Buneo et al., 2008). The analysis reveals a shift and strengthening of the reach vector as the task progresses, but it is noteworthy how clear and consistent the population $\mathrm{T}-\mathrm{H}$ coding is even as early as $300 \mathrm{~ms}$ after target onset. 


\section{Variable pair being analyzed}

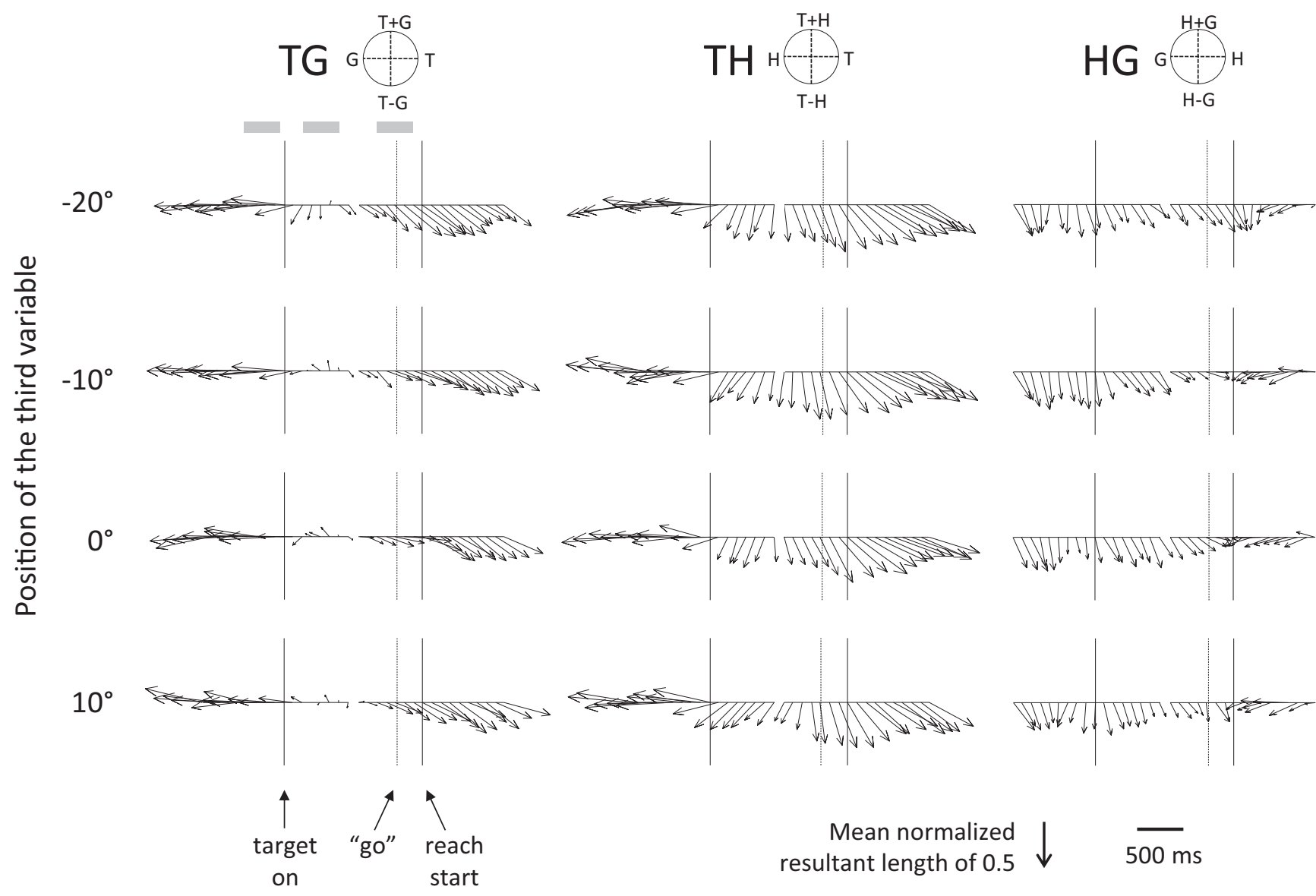

Figure 4. Time-step analysis for the population of 128 cells showing evolution of reference frames during the task. Columns show the population response to a pair of variables (e.g., TG) at each of the four positions for the third variable (e.g., H). In each subplot, the arrows represent the mean resultant for the population of cells at $100 \mathrm{~ms}$ time steps (200 ms window). Circular plots at the top of each column indicate the appropriate interpretation of arrow direction for each variable pair. Arrow length indicates the circular concentration of the matrix gradient orientations and is therefore normalized within each variable pair. Data were aligned to target onset (first solid vertical line) for the first 17 time steps and to movement onset (second solid vertical line) for the second 17 time steps, with a short gap indicating the break in alignment. The vertical dashed line indicates the mean go signal and the three shaded boxes at top left show the fixation, early delay, and late delay epochs.

The progressive increase in $\mathrm{T}-\mathrm{H}$ coding through the delay period could reflect a role for area $5 \mathrm{~d}$ in preparation for movement initiation. In primary motor cortex (M1) and dorsal premotor cortex (PMd), faster reaction times are observed on trials with higher firing rates (Riehle and Requin, 1993; Afshar et al., 2011). We analyzed the correlation between firing rates and reaction time on a trial-by-trial basis for each cell-trial-type combination and found only a slight trend toward a negative correlation (Fig. $5 C$, mean correlation coefficient $=-0.009$, $p=0.068$ ), indicating that area $5 \mathrm{~d}$ does not have a strong role in movement initiation. In marked contrast to the strong handcentered coding, gaze-centered coding of target position is absent throughout most of the delay period, only becoming weakly represented in the population during the final $400 \mathrm{~ms}$ before the reach (Fig. 4, left). This suggests that a transformation of target information from gaze centered to hand centered does not take place as a sequential process within area $5 \mathrm{~d}$. Also noticeable is the presence of hand-gaze encoding during the fixation epoch, and the gradual decay of this coding after target onset (Fig. 4, right). Our previous study examined the premovement epoch when $\mathrm{H}-\mathrm{G}$ coding is not significant in the population; the evolution of this signal is only revealed by examining the time course across the entire trial.
The normalization of population resultants within each variable pair masks the strengths of the underlying discharge modulations during the different stages of the task. For the cell shown in Figure 2, for example, the dynamic range for HG during the fixation epoch (450-50 ms before target onset) is much lower than the dynamic range for TH during the late delay epoch. However, as shown in Figure $5 B$, top, this was not reflected in the population as a whole. The distributions of dynamic ranges for these effects overlapped substantially, indicating that the $\mathrm{H}-\mathrm{G}$ coding during fixation is of comparable strength to the $\mathrm{T}-\mathrm{H}$ coding during the late delay period. However, the two distributions were significantly different when only cells with significant tuning to a variable pair were included with TH late delay having more activity than HG fixation (Kolmogorov-Smirnov test, $p=0.033$; Fig. $5 B$, bottom). Figure $5 A$ illustrates the full set of dynamic ranges, broken down by epoch and variable pair.

The very short population resultants for TG in the early part of the delay period (Fig. 4, left) could be due to a real lack of gazecentered coding or could instead be caused by, for example, a population of cells with a bimodal distribution, the peaks of which would cancel during circular averaging. Moreover, the 200 $\mathrm{ms}$ window used in the sliding time course analysis is too short to produce reliable results in the SVD analysis for separability, leav- 
A
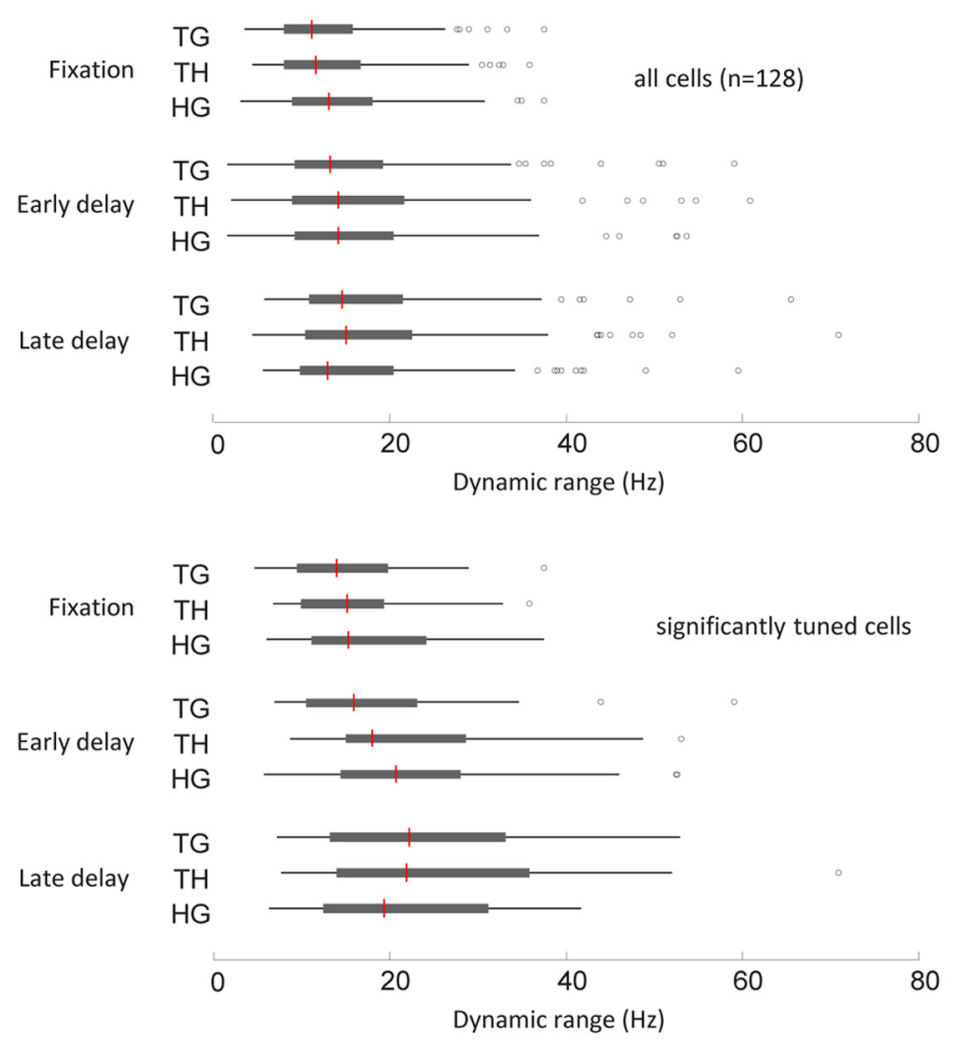

B
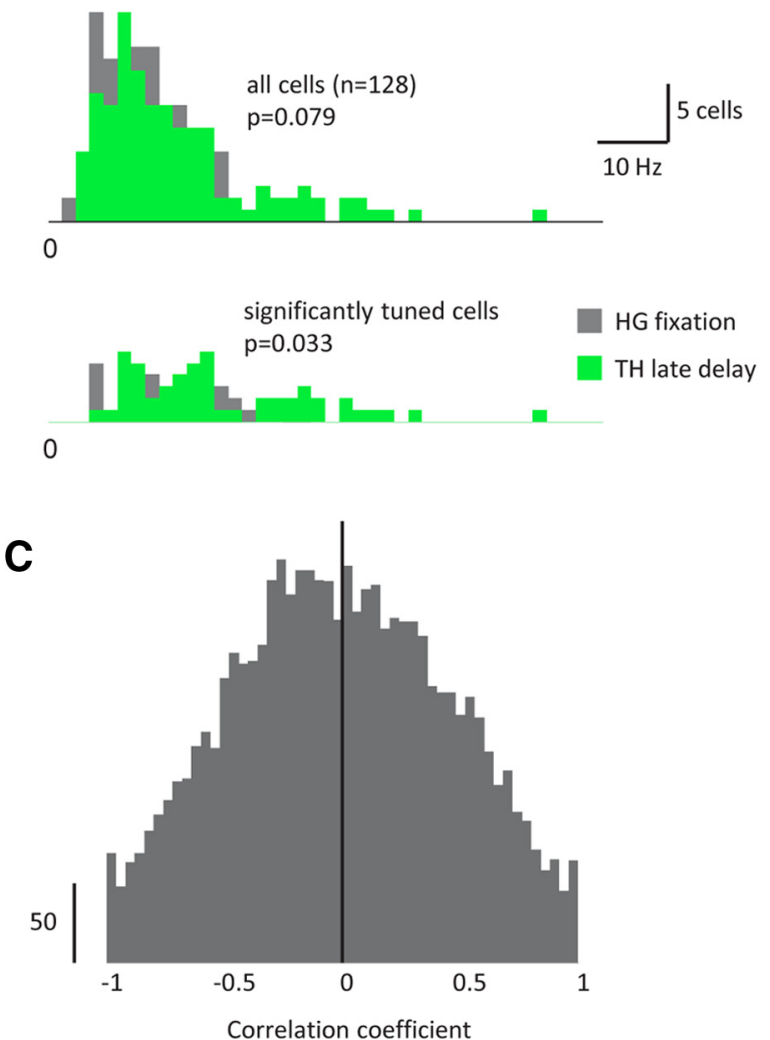

Figure 5. Dynamic range distributions by variable pair and epoch. $\boldsymbol{A}$, Box-and-whisker plots for the full set of dynamic ranges for all cells (top) and only those cells with significant tuning to the variable pair (bottom). In each case, the red line denotes the median, the solid box denotes the 25 th and 75 th percentiles, and the whiskers extend to the last data point not considered an outlier (open circles). $\boldsymbol{B}$, Histograms show in more detail the distribution of dynamic ranges for the two main effects reported: $\mathrm{HG}$ during the fixation epoch (gray) and TH during the late delay epoch (green). C, Distribution of correlation coefficients from trial-by-trial calculations of the correlation between firing rate and reaction time for individual cell-trial-type combinations.

ing open the question of whether the variables have a gain field or vector type of encoding at different stages of the task. To address these issues, we conducted a number of additional epoch analyses (Fig. 6).

In the fixation epoch $31 / 128(24 \%)$ cells had an HG matrix with a significantly long gradient resultant and were therefore classed as significantly tuned to the HG variable pair. The distribution of gradient resultant orientations for these 31 cells, together with their associated separability or inseparability, is plotted in the lower left histogram of Figure $6 \mathrm{~A}$. The majority of these cells were inseparable $(22 / 31 ; 71 \%)$, and the distribution of resultant angles was nonuniform $(p=0.002)$ with a mean orientation of $-100^{\circ}\left(95 \% \mathrm{CI}\left[-66^{\circ},-133^{\circ}\right]\right)$, confirming the finding of hand-gaze encoding at this stage in the task. Despite the results reaching significance, low firing rates and resulting noisy matrices limited the number of cells that were significantly tuned during this epoch. To counter this, we collapsed the data across upcoming "targets" to increase the number of trials per condition and improve the signal-to-noise ratio, strengthening the result [Figure $6 B ; 49 / 128(38 \%)$ cells significantly tuned; $26 / 49$ (53\%) inseparable, mean gradient resultant orientation of $-91^{\circ}(95 \%$ CI $\left.\left[-66^{\circ},-117^{\circ}\right]\right)$, significantly nonuniform distribution $(p<$ $0.0001)]$. As apparent in the sliding-window analysis, hand-gaze encoding is maintained through the early delay epoch $(200-600$ ms after target onset): 40/128 (31\%) cells are tuned to the HG variable pair, 25/40 (63\%) of these have inseparable response matrices, and the distribution is nonuniform $(p<0.001)$. The mean gradient resultant orientation, however, is $-54^{\circ}(95 \% \mathrm{CI}$ $\left.\left[-25^{\circ},-83^{\circ}\right]\right)$ in this epoch versus $-100^{\circ}$ in the fixation epoch.
Although the two distributions are not significantly different (Kuiper test) and there is overlap between the 95\% CIs for the mean in the two epochs, the trend suggests that hand position is beginning to have an increased influence over gaze position on cell firing by this point in the task. As previously published, the hand position is no longer encoded relative to gaze position in the late delay epoch [500-100 ms before movement onset; 36/128 (28\%) cells significantly tuned to the HG pair; $18 / 36$ (50\%) inseparable; distribution not significantly different from uniform].

For TG encoding, analysis of the early delay epoch showed that the distribution of resultant angles was not significantly different from uniform. Twenty-seven percent (34/128) of cells had significantly tuned firing rate matrices, of which 20/34 (59\%) were classed as inseparable. The target position and/or gaze direction influenced the firing rate in these cells, but the flat distribution demonstrates that the population did not encode the target in gaze-centered coordinates (the $\mathrm{T}-\mathrm{G}$ vector) even at this early stage in the task. The short population resultants in the sliding window analysis are therefore due to a uniform rather than bimodal distribution of individual coordinate frame resultant angles.

The epoch analysis also confirms the emergence of the reach vector in the population early after target presentation: $39 / 128$ cells had significantly tuned $\mathrm{TH}$ matrices during the early delay epoch, of which 23/39 (59\%) were inseparable, and the distribution was significantly nonuniform $(p<0.0001)$. However, the distributions for TH differ significantly between the early and late delay periods $(p<0.005$, Kuiper test), re- 
A

Fixation

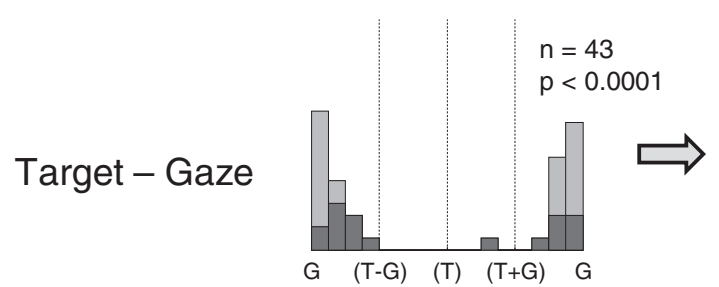

Early delay
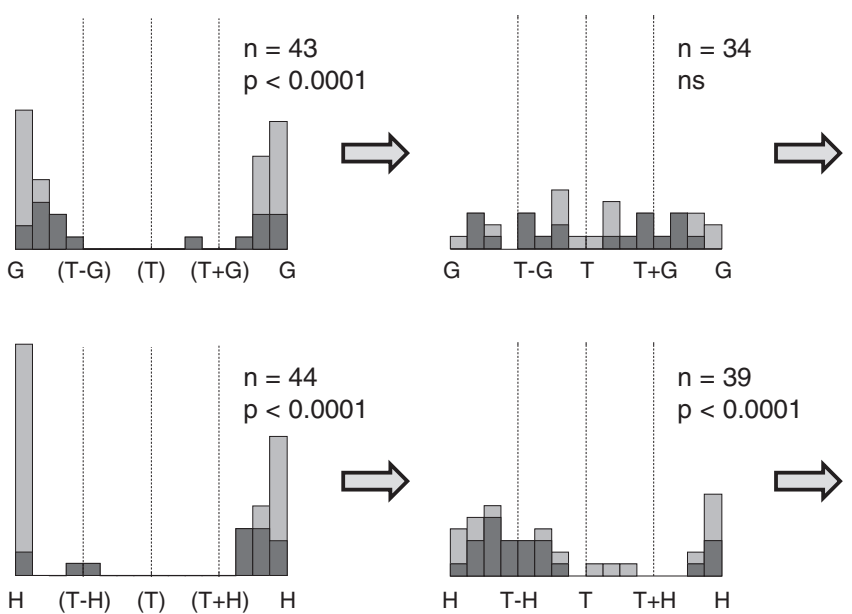

Target - Hand

Hand - Gaze

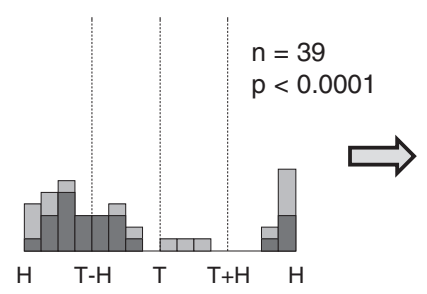

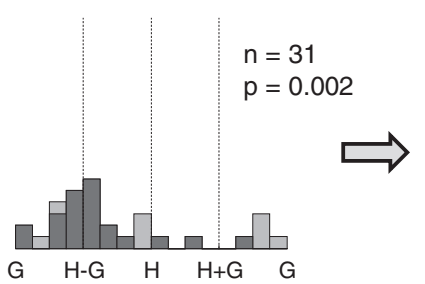
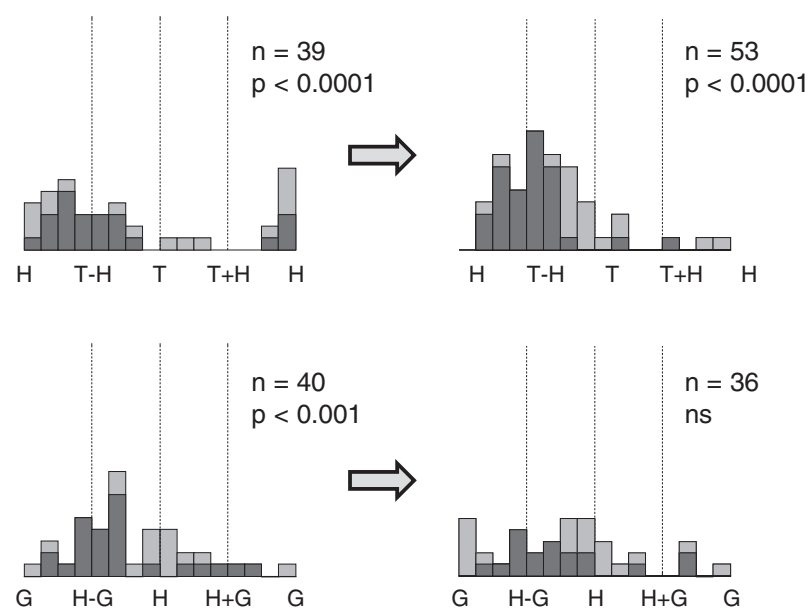

20

number

of cells

0

B

Gradient resultant orientation
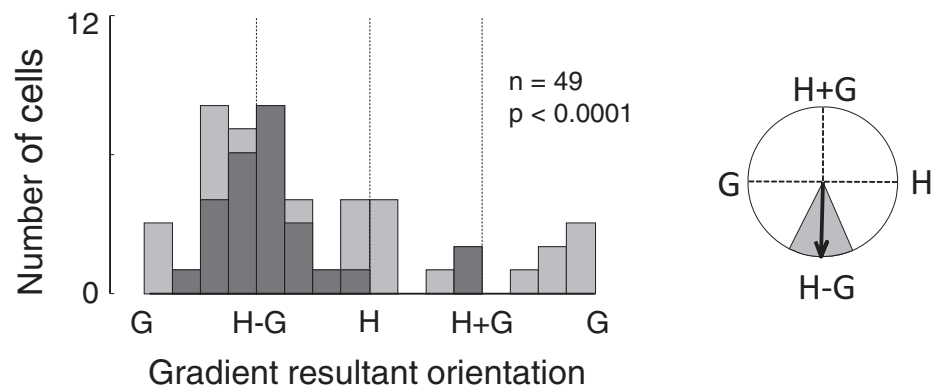

Figure 6. Area $5 \mathrm{~d}$ codes the hand position relative to gaze before target presentation, but codes the reach vector as movement onset approaches. $\boldsymbol{A}$, Histograms show the distribution of orientations of the matrix gradient resultants and SVD analysis for the population of tuned cells at three epochs during the task (fixation, early delay, and late delay). Each stacked bar represents $22.5^{\circ}$ of the circular orientation plot; pale gray indicates separable responses and dark gray indicates inseparable responses. $p$ values show the results of the Rayleigh test for uniformity, corrected for multiple comparisons. $\boldsymbol{B}$, Histogram for the HG variable pair as described in $\boldsymbol{A}$, but showing results when trials were collapsed across upcoming target positions (left). Mean gradient resultant orientation when trials were collapsed was $-91^{\circ}$; the shaded area represents $95 \%$ confidence limits (right).

flecting both a shift in mean gradient orientation [from $-134^{\circ}$ $\left(95 \%\right.$ CI $\left.\left[-110^{\circ},-157^{\circ}\right]\right)$ to $-73^{\circ}\left(95 \%\right.$ CI $\left.\left.\left[-57^{\circ},-89^{\circ}\right]\right)\right]$ and the strengthening of the $\mathrm{T}-\mathrm{H}$ representation in the population (from $n=39$ to $n=53$ cells with significant tuning) as the movement onset approaches.

\section{Recruitment of neuronal subpopulations at different time points}

The time-dependent increase in the number of cells significantly tuned for the TH matrix raises an important issue: Are the observed changes in the population response a result of the dynamic nature of representations within individual neurons during the task, or is there instead differential recruitment of neuronal subpopulations, with each subpopulation coding in a static reference frame? The example cell in Figures 2 and 3 has both decaying
$\mathrm{H}-\mathrm{G}$ encoding and increasing $\mathrm{T}-\mathrm{H}$ encoding, so reference frames are not necessarily unitary or static within a single cell. Thirteen percent $(16 / 128)$ of cells were similarly tuned for HG during the fixation epoch followed by $\mathrm{TH}$ during the late delay epoch. However, this does not preclude additional changes in subpopulation recruitment.

The Venn diagram in Figure $7 A$ illustrates that 13 cells were significantly tuned to the HG variable pair in both fixation and late delay epochs, but a majority of tuned cells $(18+23=41)$ was significantly tuned to HG in only one of these epochs. A similar breakdown can be seen when looking at the TH tuning in the early and late delay epochs: 22 cells are tuned in both epochs, whereas 48 cells are tuned in only one of the epochs, with a substantially larger proportion of these tuned in the late delay $(n=31)$ versus the early delay $(n=17)$ epoch (Fig. $7 B)$. This 


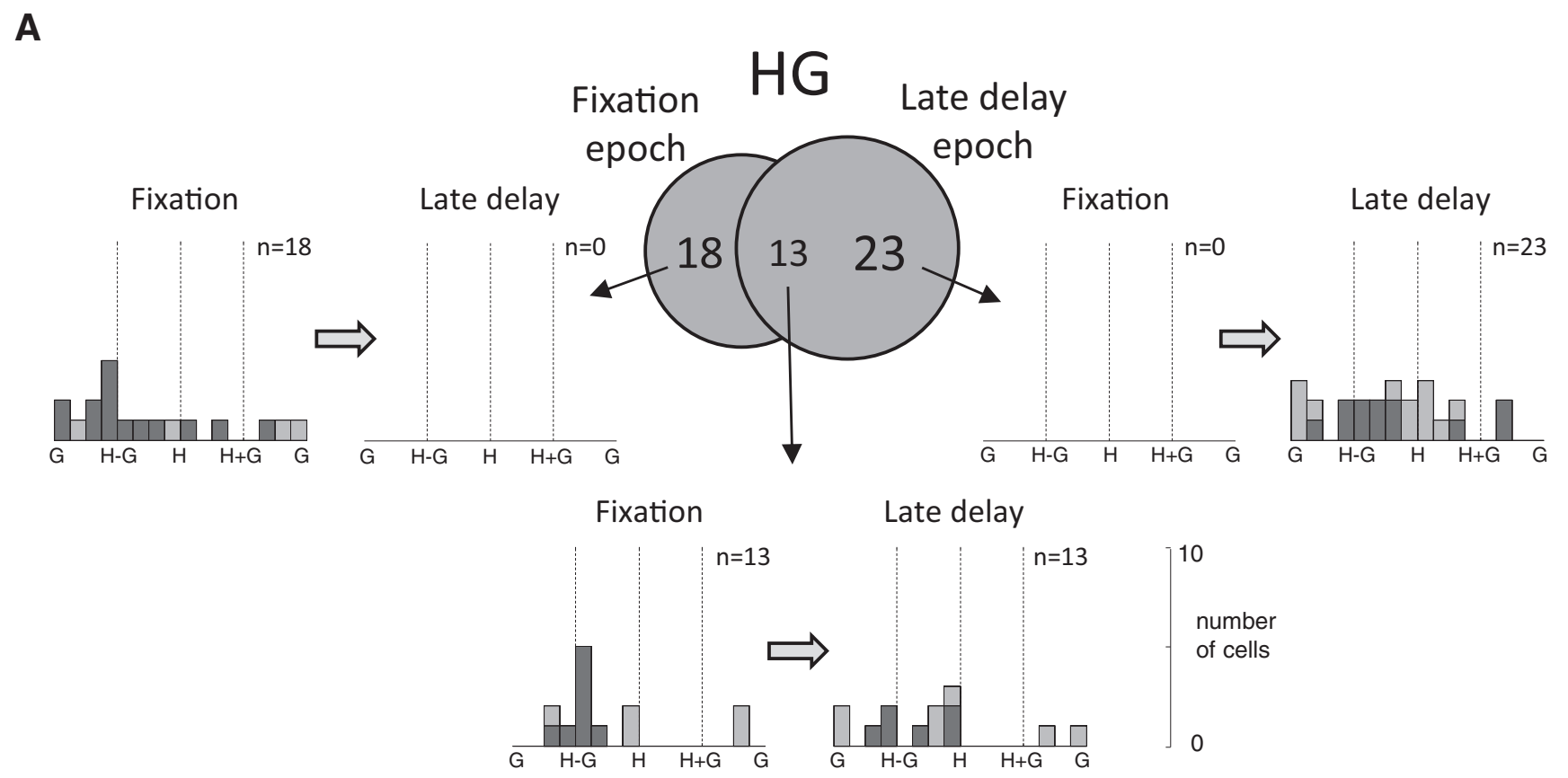

B
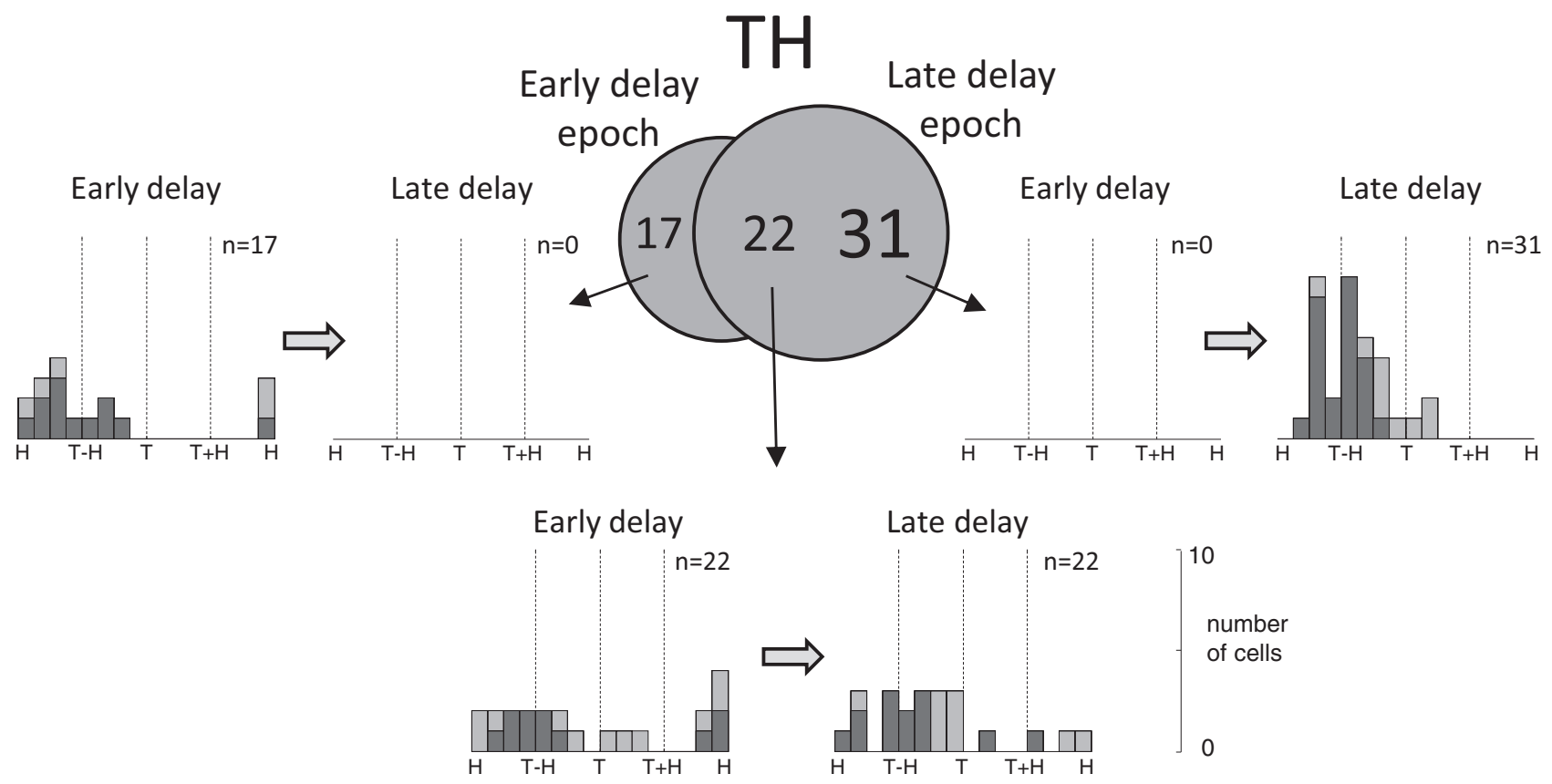

Figure 7. Differential recruitment of subpopulations across epochs. Venn diagrams show the numbers of cells significantly tuned to the HG variable pair during the fixation and late delay epochs $(\boldsymbol{A})$ and to the TH variable pair during the early delay and late delay epochs ( $\boldsymbol{B}$ ). Some cells were tuned only within a single epoch, whereas others were tuned during both epochs. Histograms show the orientations of the matrix gradient resultants and SVD analysis for each subgroup of cells in the Venn diagram across the specified epochs. Stacked bars represent separable (pale gray) or inseparable (dark gray) responses.

suggests that independent subsets of neurons contribute differentially to the population resultant at different time points in the task.

\section{Discussion}

In this study, we investigated how sensorimotor reference frames develop over time in parietal area $5 \mathrm{~d}$ during the course of a delayed reaching task. The experimental design included a large number of different combinations of hand, gaze, and target positions that allowed us to examine this question in detail. Our study reveals the existence of temporal changes in the neural representations in area $5 \mathrm{~d}$ both across different epochs of the task and as the reach movement approaches.

In particular, we show that the reference frame used during the pretarget, fixation period appears to be different from that used in later stages of the task. Previous studies have shown a general dominance in this region for signals involving the hand, arm, and shoulder rather than the gaze, and also a specific lack of hand-gaze encoding during the late delay period (Georgopoulos and Massey, 1985; Ferraina and Bianchi, 1994; Scott et al., 1997; 
Bremner and Andersen, 2012). We therefore anticipated that cells would encode the position of the hand in body-centered or extrinsic space during the fixation epoch, similar to that reported by Lacquaniti et al. (1995). Instead we found that hand position is in fact coded relative to gaze location at this point in the task, possibly reflecting the immediate behavioral goal of maintaining hand and gaze fixation. The source of this signal could be the PRR or PMd, both of which have similar $\mathrm{H}-\mathrm{G}$ encoding during the fixation period (Chang et al., 2009; Pesaran et al., 2010, their supplemental material). The $\mathrm{H}-\mathrm{G}$ signal is not maintained throughout the task, but becomes progressively weaker in the population once the reach target is present and the behavioral goal is shifted toward planning the upcoming reach.

Psychophysical studies have shown that sensorimotor integration can be context dependent (Vetter and Wolpert, 2000; Kording and Wolpert, 2004; Sober and Sabes, 2005). Recent fMRI experiments further demonstrated that the reference frame in which a motor goal is encoded in human posterior parietal cortex depends on the sensory modality through which the target is presented, with flexible switching occurring between the different representations (Bernier and Grafton, 2010). Similarly, our results suggest that neural responses in area $5 \mathrm{~d}$ may represent postural information in the reference frame that is most appropriate at each stage in the task.

An alternative explanation that we cannot rule out is that the animals may be covertly forming a default reach plan during the fixation period. Before the presence of an explicit target, the most naturalistic behavior is to reach toward the location of gaze, in which case the planned "reach" vector would be $\mathrm{H}-\mathrm{G}$. This default plan would be replaced by the actual reach plan after target onset, and the activity in area $5 \mathrm{~d}$ would at all times be representing the reach vector in the current plan, either default (during the fixation period) or actual (during the delay period). This hypothesis could also explain why hand and gaze are encoded in a vector form during the fixation period despite being independently manipulated. Cells in area $5 \mathrm{~d}$ do not typically respond in the delay period during planning of saccades. It would therefore be interesting to record from neurons during interleaved reach and saccade planning trials to see whether the $\mathrm{H}-\mathrm{G}$ activity we observed in the fixation epoch is also present when the default movement plan would be for a saccade rather than a reach.

Second, we show that the pooled population response in area $5 \mathrm{~d}$ is not static even after the onset of the reach target. During the delay period, the reach vector $\mathrm{T}-\mathrm{H}$ is the dominant representation in the population, compared with $\mathrm{T}-\mathrm{G}$ and $\mathrm{H}-\mathrm{G}$, and remains so until movement execution, consistent with previous reports of time-invariant reference frames in posterior parietal cortex (Buneo et al., 2008; Lehmann and Scherberger, 2013). However, both the sliding window and epoch analyses show for the first time that the population $\mathrm{T}-\mathrm{H}$ representation is not static during this time but builds in strength from target onset to movement onset, in part due to recruitment of additional tuned cells. The timing of this increase corresponds with an increase in firing rate commonly observed in the later stages of the delay period in area $5 \mathrm{~d}$ cells and may reflect anticipatory activity, although trialby-trial analysis of the correlation between firing rate and reaction time did not reveal a prominent role for area $5 \mathrm{~d}$ in initiating the reach. The previous study by Buneo et al. (2008) reported invariance of reference frames over time in a sliding window analysis. However, they used variability in firing rate to assess the best-fitting reference frame and it is likely that this different outcome measure explains the difference between their results and those reported here. In addition, our study used a comprehensive set of trial types enabling us to take a more detailed approach to the question.

Our results also show a striking lack of gaze-centered coding for target position $(T-G)$ during the early delay period. This is when the visual target first appears, and it might be expected that there would be at least a brief gaze-centered response at the onset of the visual stimulus. There is some influence of gaze position on firing rate for a subset of cells, but the combined SVD and gradient analysis demonstrates that this is limited to nonsystematic effects (Fig. 6A). The example cell in Figure $2 A$ shows a small visual-related response but, in general, cells in area $5 \mathrm{~d}$ have little increase in firing with the onset of a visual cue and instead ramp up their activity as the time of movement onset approaches. This is in contrast to neighboring PRR where cells usually show a clear cue-related peak, followed by sustained firing during the delay period (see Cui and Andersen, 2011, Figure 3, for examples of population responses for PRR and area 5d). PRR has been found to code reach targets in a predominantly gaze-centered reference frame (Andersen et al., 1998; Batista et al., 1999; Buneo et al., 2002; Cohen and Andersen, 2002; Pesaran et al., 2006, but see Mullette-Gillman et al., 2005, 2009; Chang and Snyder, 2010; McGuire and Sabes, 2011). There is no a priori reason why cells that code an upcoming reach movement relative to the direction of gaze should also have visually evoked responses. However, in terms of the overall flow of information in the brain-from retinotopic inputs to motor output-earlier processing stages would seem to be more likely to respond directly to a visual stimulus, with this response diminishing in later stages.

While we cannot rule out the possibility of an extremely rapid gaze-centered response that was too transient to be captured in the $200 \mathrm{~ms}$ sliding window, our temporal analysis strongly suggests that there is no progression from sensory to motor reference frames within area $5 \mathrm{~d}$. Instead, it is likely that area $5 \mathrm{~d}$ is downstream of the transformation, reading out the results of a computation taking place in other regions or circuits, such as the reciprocal circuit between the PRR and PMd. Our results are consistent with computational models in which the input layer (e.g., gaze-centered spatial information) is mapped to the output layer (e.g., hand or body-centered spatial information) via an intermediate or hidden layer (Zipser and Andersen, 1988; Pouget and Snyder, 2000; Xing and Andersen, 2000). Once such circuits are established, the sensorimotor transformation can occur almost immediately, in only the time it takes for signals to propagate through the network. The gain modulated properties of cells in PRR (Andersen et al., 1998; Chang et al., 2009) and the relative coding scheme in PMd (Pesaran et al., 2006, 2010) suggest that these nodes in the frontoparietal reaching circuit may be candidates for the hidden layer, with area $5 \mathrm{~d}$ serving as an output layer.

The function of this output layer may be to combine plans for future movement with sensory feedback and efference copy of motor commands to form an accurate estimate of the current and upcoming limb dynamics. The brain is thought to generate such an internal forward model of the arm to reduce the instability in movements that would occur if the system relied solely on the relatively slow visual and proprioceptive signals from the periphery for feedback (Wolpert and Miall, 1996; Desmurget and Grafton, 2000). Evidence from lesion studies and transcranial magnetic stimulation in humans, as well as neurophysiological studies in monkeys, has long pointed to the superior parietal lobe as a critical node in the network responsible for on-line control of limb movement through state estimation (Georgopoulos et al., 1984; Lacquaniti et al., 1995; Wolpert et al., 1998; Desmurget et al., 1999; Pisella et al., 2000; Gréa et al., 2002; Galletti et al., 2003; 
Della-Maggiore et al., 2004; Battaglia-Mayer et al., 2013). The observed strengthening of the reach vector $(\mathrm{T}-\mathrm{H})$ described above suggests that area $5 \mathrm{~d}$ is not merely reading out the pending motor plan, which would require no change in strength of tuning as the delay period progresses, but may instead be involved in building the state estimate for the limb. Previous studies of area $5 \mathrm{~d}$ during reaches and joystick movements have found neurons that reflect the arm or cursor trajectory with timing slower than required for the outgoing motor command yet more rapid than would be expected for incoming sensory feedback (Mulliken et al., 2008; Archambault et al., 2009, 2011). Such intermediate timing is suggestive of area $5 \mathrm{~d}$ as the locus for a forward model of the arm within the superior parietal lobe. In the delayed reaching task used in the current study the arm was stationary during all measured epochs so that we could accurately assess the reference frame(s); we therefore cannot make inferences about area $5 \mathrm{~d}$ as a potential forward model. However, it is worth noting that the population gradient resultant orientations for $\mathrm{TH}$ in the time after the start of the reach shift increasingly from $\mathrm{T}-\mathrm{H}$ toward $\mathrm{T}$ (Fig. 4, center column). At this point in the task, the hand $(\mathrm{H})$ is not fixed but is moving toward and ultimately converges on the target position $(\mathrm{T})$ : in other words $\mathrm{T}=\mathrm{H}$ at the moment of target acquisition. The shift in matrix gradient orientation after movement onset indicates that area $5 \mathrm{~d}$ is reflecting the convergence of the hand onto the target. We did not formally analyze the movement epoch because we did not track hand motion once the hand had left the touch screen, but this pattern is consistent with first planning and then on-line coding of the reaching trajectory. Interestingly, similar conclusions were drawn from the results of an earlier reaching study in which the activity of subsets of area 5 neurons was observed to be related to the initial or upcoming position of the limb (Lacquaniti et al., 1995), though eye position was not controlled or monitored in that study.

There are several caveats to our results. Neurons in area $5 \mathrm{~d}$ are heterogeneous in their responses: $23 \%$ of all our recorded neurons did not respond in a spatially tuned way to the reaching task. This suggests that, in common with other high-level cortical regions, area $5 \mathrm{~d}$ almost certainly serves multiple functions, of which a possible role in state estimation is only one. Second, it was not experimentally feasible to test for all potential representations or transformations, such as head centered, body centered, or shoulder centered, and reaches were confined to the range -20 to $10^{\circ}$. However, had it been practical to track more representations across a wider spatial range, we would not expect this to alter our finding that reference frames in area $5 \mathrm{~d}$ are modulated during reach planning. Simultaneous recording from a population of cells would shed further light on the temporal dynamics of reference frame encoding, but was beyond the scope of the current study.

\section{References}

Afshar A, Santhanam G, Yu BM, Ryu SI, Sahani M, Shenoy KV (2011) Single-trial neural correlates of arm movement preparation. Neuron 71: 555-564. CrossRef Medline

Andersen RA, Cui H (2009) Intention, action planning, and decision making in parietal-frontal circuits. Neuron 63:568-583. CrossRef Medline

Andersen RA, Mountcastle VB (1983) The influence of the angle of gaze upon the excitability of the light-sensitive neurons of the posterior parietal cortex. J Neurosci 3:532-548. Medline

Andersen RA, Snyder LH, Batista AP, Buneo CA, Cohen YE (1998) Posterior parietal areas specialized for eye movements (LIP) and reach (PRR) using a common coordinate frame. Novartis Found Symp 218:109-122; discussion 122-108, 171-105. Medline

Archambault PS, Caminiti R, Battaglia-Mayer A (2009) Cortical mecha- nisms for online control of hand movement trajectory: the role of the posterior parietal cortex. Cereb Cortex 19:2848-2864. CrossRef Medline Archambault PS, Ferrari-Toniolo S, Battaglia-Mayer A (2011) Online control of hand trajectory and evolution of motor intention in the parietofrontal system. J Neurosci 31:742-752. CrossRef Medline

Avillac M, Denève S, Olivier E, Pouget A, Duhamel JR (2005) Reference frames for representing visual and tactile locations in parietal cortex. Nat Neurosci 8:941-949. CrossRef Medline

Batista AP, Buneo CA, Snyder LH, Andersen RA (1999) Reach plans in eyecentered coordinates. Science 285:257-260. CrossRef Medline

Battaglia-Mayer A, Ferrari-Toniolo S, Visco-Comandini F, Archambault PS, Saberi-Moghadam S, Caminiti R (2013) Impairment of online control of hand and eye movements in a monkey model of optic ataxia. Cereb Cortex 23:2644-2656. CrossRef Medline

Bernier PM, Grafton ST (2010) Human posterior parietal cortex flexibly determines reference frames for reaching based on sensory context. Neuron 68:776-788. CrossRef Medline

Bremner LR, Andersen RA (2012) Coding of the reach vector in parietal area 5d. Neuron 75:342-351. CrossRef Medline

Buneo CA, Jarvis MR, Batista AP, Andersen RA (2002) Direct visuomotor transformations for reaching. Nature 416:632-636. CrossRef Medline

Buneo CA, Batista AP, Jarvis MR, Andersen RA (2008) Time-invariant reference frames for parietal reach activity. Exp Brain Res 188:77-89. CrossRef Medline

Caminiti R, Ferraina S, Mayer AB (1998) Visuomotor transformations: early cortical mechanisms of reaching. Curr Opin Neurobiol 8:753-761. CrossRef Medline

Chang SW, Snyder LH (2010) Idiosyncratic and systematic aspects of spatial representations in the macaque parietal cortex. Proc Natl Acad Sci U S A 107:7951-7956. CrossRef Medline

Chang SW, Papadimitriou C, Snyder LH (2009) Using a compound gain field to compute a reach plan. Neuron 64:744-755. CrossRef Medline

Cohen YE, Andersen RA (2002) A common reference frame for movement plans in the posterior parietal cortex. Nat Rev Neurosci 3:553-562. CrossRef Medline

Cui H, Andersen RA (2011) Different representations of potential and selected motor plans by distinct parietal areas. J Neurosci 31:18130-18136. CrossRef Medline

Della-Maggiore V, Malfait N, Ostry DJ, Paus T (2004) Stimulation of the posterior parietal cortex interferes with arm trajectory adjustments during the learning of new dynamics. J Neurosci 24:9971-9976. CrossRef Medline

Desmurget M, Grafton S (2000) Forward modeling allows feedback control for fast reaching movements. Trends Cogn Sci 4:423-431. CrossRef Medline

Desmurget M, Epstein CM, Turner RS, Prablanc C, Alexander GE, Grafton ST (1999) Role of the posterior parietal cortex in updating reaching movements to a visual target. Nat Neurosci 2:563-567. CrossRef Medline

Ferraina S, Bianchi L (1994) Posterior parietal cortex: functional properties of neurons in area 5 during an instructed-delay reaching task within different parts of space. Exp Brain Res 99:175-178. Medline

Galletti C, Kutz DF, Gamberini M, Breveglieri R, Fattori P (2003) Role of the medial parieto-occipital cortex in the control of reaching and grasping movements. Exp Brain Res 153:158-170. CrossRef Medline

Georgopoulos AP, Massey JT (1985) Static versus dynamic effects in motor cortex and area 5: comparison during movement time. Behav Brain Res 18:159-166. CrossRef Medline

Georgopoulos AP, Caminiti R, Kalaska JF (1984) Static spatial effects in motor cortex and area 5: quantitative relations in two-dimensional space. Exp Brain Res 54:446-454. Medline

Gréa H, Pisella L, Rossetti Y, Desmurget M, Tilikete C, Grafton S, Prablanc C, Vighetto A (2002) A lesion of posterior parietal cortex disrupts on-line adjustments during aiming movements. Neuropsychologia 40:24712480. CrossRef Medline

Kording KP, Wolpert DM (2004) Bayesian integration in sensorimotor learning. Nature 427:244-247. CrossRef

Lacquaniti F, Guigon E, Bianchi L, Ferraina S, Caminiti R (1995) Representing spatial information for limb movement: role of area 5 in the monkey. Cereb Cortex 5:391-409. CrossRef Medline

Lehmann SJ, Scherberger H (2013) Reach and gaze representations in macaque parietal and premotor grasp areas. J Neurosci 33:7038-7049. CrossRef Medline 
McGuire LM, Sabes PN (2011) Heterogeneous representations in the superior parietal lobule are common across reaches to visual and proprioceptive targets. J Neurosci 31:6661-6673. CrossRef Medline

Mullette-Gillman OA, Cohen YE, Groh JM (2005) Eye-centered, headcentered, and complex coding of visual and auditory targets in the intraparietal sulcus. J Neurophysiol 94:2331-2352. CrossRef Medline

Mullette-Gillman OA, Cohen YE, Groh JM (2009) Motor-related signals in the intraparietal cortex encode locations in a hybrid, rather than eyecentered reference frame. Cereb Cortex 19:1761-1775. CrossRef Medline

Mulliken GH, Musallam S, Andersen RA (2008) Forward estimation of movement state in posterior parietal cortex. Proc Natl Acad Sci U S A 105:8170-8177. CrossRef Medline

Peña JL, Konishi M (2001) Auditory spatial receptive fields created by multiplication. Science 292:249-252. CrossRef Medline

Pesaran B, Nelson MJ, Andersen RA (2006) Dorsal premotor neurons encode the relative position of the hand, eye, and goal during reach planning. Neuron 51:125-134. CrossRef Medline

Pesaran B, Nelson MJ, Andersen RA (2010) A relative position code for saccades in dorsal premotor cortex. J Neurosci 30:6527-6537. CrossRef Medline

Pisella L, Gréa H, Tilikete C, Vighetto A, Desmurget M, Rode G, Boisson D, Rossetti Y (2000) An 'automatic pilot' for the hand in human posterior parietal cortex: toward reinterpreting optic ataxia. Nat Neurosci 3:729736. CrossRef Medline
Pouget A, Snyder LH (2000) Computational approaches to sensorimotor transformations. Nat Neurosci 3 [Suppl]:1192-1198. Medline

Riehle A, Requin J (1993) The predictive value for performance speed of preparatory changes in neuronal activity of the monkey motor and premotor cortex. Behav Brain Res 53:35-49. CrossRef Medline

Scott SH, Sergio LE, Kalaska JF (1997) Reaching movements with similar hand paths but different arm orientations. II. Activity of individual cells in dorsal premotor cortex and parietal area 5. J Neurophysiol 78:2413-2426. Medline

Sober SJ, Sabes PN (2005) Flexible strategies for sensory integration during motor planning. Nat Neurosci 8:490-497. Medline

Vetter P, Wolpert DM (2000) Context estimation for sensorimotor control. J Neurophysiol 84:1026-1034. Medline

Wolpert DM, Miall RC (1996) Forward Models for Physiological Motor Control. Neural Netw 9:1265-1279. CrossRef Medline

Wolpert DM, Goodbody SJ, Husain M (1998) Maintaining internal representations: the role of the human superior parietal lobe. Nat Neurosci 1:529-533. CrossRef Medline

Xing J, Andersen RA (2000) Models of the posterior parietal cortex which perform multimodal integration and represent space in several coordinate frames. J Cogn Neurosci 12:601-614. CrossRef Medline

Zipser D, Andersen RA (1988) A back-propagation programmed network that simulates response properties of a subset of posterior parietal neurons. Nature 331:679-684. CrossRef Medline 